\title{
SAÚdE MENTAL EM CONTEXTOS DE PANDEMIA E ISOLAMENTO SOCIAL: TAREFAS PARA AS TRABALHADORAS E TRABALHADORES DA SAÚDE
}

\author{
MENTAL HEALTH IN CONTEXTS OF PANDEMIC AND \\ SOCIAL ISOLATION: TASKS FOR HEALTH WORKERS
}

DOI: http://dx.doi.org/10.16891/2317-434X.v8.e3.a2020.pp657-666 Recebido em: 02.08.2020 | Aceito em: 30.09 .2020

\author{
Renan Vieira de Santana Rocha*a, Beatriz Borges Brambilla ${ }^{b}$, Brenda Dantas Barros ${ }^{c}$ \\ Instituto de Saúde Coletiva da UFBA ${ }^{a}$ \\ Pontifícia Universidade Católica de São Paulo - PUC-SPb \\ Universidade Presbiteriana Mackenzie ${ }^{c}$ \\ *E-mail: renanvsr@gmail.com
}

\section{RESUMO}

O contexto de pandemia que temos vivenciado, iniciado em 2020, tem gerado impactos psicossociais em diferentes esferas da vida cotidiana, o que demanda das trabalhadoras e trabalhadores da saúde o desenvolvimento de saberes e fazeres profissionais atentos às questões de nosso tempo-espaço. Logo, o presente estudo enseja, a partir de um ensaio teórico-crítico, apontar o que algumas pesquisas importantes, publicadas neste mesmo ano, em nível internacional, têm nos indicado acerca das questões de Saúde Mental neste período. Tal e qual, a partir destas análises - que nos revelam a existência de impactos psicossociais de âmbito muito mais social, econômico e político, do que em termos tradicionalmente epidemiológicos - ensejamos também ponderar quais as possíveis tarefas que se revelam a estas mesmas trabalhadoras e trabalhadores, especialmente a partir de uma análise crítica dos comportamentos assumidos pelo Governo Federal brasileiro, em termos do enfrentamento à pandemia decorrente do novo coronavírus. Assim, concluímos que tais tarefas se configuram em ações de: (10) Execução de serviços essenciais; ( $2^{\circ}$ ) Compromisso com a divulgação de informações qualificadas; $\left(3^{\circ}\right)$ Evitação ao pânico e convocação à responsabilização coletiva; (40) Evidenciação de grupos em maior risco, por conta da desigualdade social; (50) Defesa das Políticas Públicas, com destaque ao SUS e ao SUAS, enquanto sistemas públicos, gratuitos e de qualidade; e $\left(6^{\circ}\right)$ Coletivização ético-política da contemporaneidade.

Palavras-chave: Saúde Mental; Trabalhadores de Saúde; COVID-19.

\section{ABSTRACT}

The pandemic context that we have been experiencing, initiated in 2020, has psychosocial impacts in different spheres of daily life, which requires health workers to develop knowledge and professional practices that are attentive to the issues of our time-space. Therefore, the present study suggests, based on a theoretical-critical essay, to point out that some important researches, released the same year, at an international level, have guidelines on mental health issues in this period. As such, from these analyzes - which reveal the existence of psychosocial impacts of a much more social, economic and political scope, than in traditional epidemiological terms - we also have the opportunity to consider what are possible tasks that are revealed to these workers, especially from a critical analysis of the behaviors assumed by the Brazilian Federal Government, in terms of facing the pandemic resulting from the new coronavirus. Thus, we conclude that such tasks are configured in actions of: (1st) Execution of essential services; (2nd) Commitment to the disclosure of qualified information; (3rd) Avoidance of panic and call for collective accountability; (4th) Disclosure of groups at greatest risk, due to social inequality; (5th) Defense of Public Policies, with emphasis on SUS and SUAS, as public, free and quality systems; and (6th) Ethical-political collectivization of contemporary times.

Keyword: Mental Health; Health Workers; COVID-19. 


\section{INTRODUÇÃO:}

Ou preâmbulo para pensar a saúde mental em contextos de pandemia e isolamento social

A saúde mental constitui-se em um campo de saberes e fazeres muito diversos (AMARANTE, 2007). A partir dela, pensamos, enquanto trabalhadoras e trabalhadores da saúde, nas condições de vida, saúde e adoecimento das diferentes populações, sempre atentas/os aos impactos psicossociais decorrentes dos fenômenos da contemporaneidade a estas mesmas condições. Logo, produzir saúde mental, especialmente no Brasil, não se constitui em um ato simples ou meramente semiológico (focado em sinais e sintomas) e/ou nosológico (focado em classificações psiquiátricas, estruturadas a partir dos grandes manuais de psiquiatria, como a CID-11 e o DSM5). Produzir saúde mental, para nós, é pensar em atos contínuos de cuidado, atentas/os às questões sociais, políticas e econômicas que influenciam as relações humanas, reconhecendo, inclusive, que todas as pessoas sofrem, mas em diferentes intensidades, com diferentes agravos e diferentes necessidades de saúde (ALVES; RODRIGUES, 2010; ROCHA; COELHO, 2017). Sobre isto, dizem-nos Alves e Rodrigues (2010):

Enquanto os cuidados médicos podem melhorar a sobrevida e o prognóstico de algumas doenças graves, mais importante para a saúde da população como um todo são as condições sociais e econômicas que podem, em primeiro lugar, contribuir para o adoecer e para a necessidade de cuidados médicos [e em saúde, de forma geral] (ibidem, p. 130, grifo nosso).

Nesta linha, diferentes contextos, influenciados pelas questões de tempo e espaço, podem também, de alguma forma, determinar acessos e inacessos a bens e serviços de saúde, bem como marcar modos de épocas e demarcar movimentos de gerações muito específicos, inclusive em termos de sua própria saúde mental. É o que constatamos, por exemplo, a partir de uma análise dos impactos psicossociais que temos visualizado no que concerne à atual pandemia relacionada ao novo coronavírus (COVID-19/SARS-CoV-2). Sobre isto, a Fundação Oswaldo Cruz (Fiocruz), importante entidade do setor saúde nacional, em documento publicado em março de 2020, já nos alertava sobre os possíveis efeitos que um contexto epidêmico/pandêmico poderia ocasionar à sociedade, em termos destes diferentes impactos psicossociais:

Durante uma pandemia é esperado que estejamos frequentemente em estado de alerta, preocupados, confusos, estressados e com sensação de falta de controle frente às incertezas do momento.
Estima-se que entre um terço e metade da população exposta a uma epidemia pode vir a sofrer alguma manifestação psicopatológica, caso não seja feita nenhuma intervenção de cuidado específico para as reações e sintomas manifestados. Os fatores que influenciam o impacto psicossocial estão relacionados à magnitude da epidemia e ao grau de vulnerabilidade em que a pessoa se encontra no momento. Entretanto, é importante destacar que nem todos os problemas psicológicos e sociais apresentados poderão ser qualificados como doenças. A maioria será classificado como reações normais diante de uma situação anormal. A pandemia impacta os seres humanos de maneiras específicas, vistas as suas características (FIOCRUZ, 2020, p. 02, grifo nosso).

O que segue apontado acima, pela Fiocruz (2020), encontra coro em outros documentos publicados por entidades da saúde nacionais e internacionais neste momento, ao evidenciar que o que se vive em contextos epidêmicos/pandêmicos, indubitavelmente, gera ecos e ressonâncias aos processos saúde-doença-cuidado para as diferentes pessoas, de diferentes populações, em diferentes esferas da saúde (OMS, 2020; IASC, 2020).

Estes reconhecimentos iniciais, por sua vez, nos levam a quatro ponderações preliminares importantes: $\left(1^{\mathrm{a}}\right)$ um contexto de epidemia/pandemia afeta a vida e o cotidiano das pessoas, produzindo eventuais impactos psicossociais; $\left(2^{\mathrm{a}}\right)$ estes mesmos impactos psicossociais não são decorrentes, tão somente, de condições orgânicas e/ou psicopatológicas, mas sim expressões que podem/devem ser compreendidas como absolutamente possíveis frente ao contexto supracitado; $\left(3^{a}\right)$ estes mesmos impactos psicossociais precisam ser observados, também, a partir das idiossincrasias - ou seja, das particularidades - mas sem deixar de observá-los, tal e qual, como manifestações estruturadas no contexto social, político e econômico que circunda a epidemia/pandemia; e $\left(4^{a}\right)$ surge às trabalhadoras e trabalhadores da saúde a missão de pensar em modos de produzir saúde/cuidado frente a tais questões, já que, a estas pessoas, incumbe-se a premissa de que sejam capazes de operar reflexões e ações sobre a saúde mental da população como um todo, mas também a partir de suas especificidades (FIOCRUZ, 2020; OMS, 2020; IASC, 2020).

É partindo destes reconhecimentos que nos propomos a apresentar o presente estudo, estruturado sob o formato de um ensaio teórico-crítico - método que apresentaremos em seguida. Ensejamos, assim, em uma primeira instância, realizar uma análise dos artigos publicados entre os meses de janeiro e junho de 2020, que transversalizam o debate entre a Saúde Mental e a COVID-19, junto à revista The Lancet (BROOKS et al, 2020; MORENO et al, 2020; PIERCE et al, 2020) - revista 
cuja escolha melhor apresentaremos mais à frente.

Em segunda instância, mas articulada com a primeira, por conseguinte, ensejamos pensar quais as demandas que se revelam às trabalhadoras e trabalhadores da saúde frente aos dados constatados nos estudos em questão, correlacionando tais resultados com uma análise crítica dos comportamentos assumidos pelo Governo Federal brasileiro, em termos do enfrentamento à pandemia decorrente do novo coronavírus, evidenciada a partir de um conjunto selecionado de notícias publicadas no corrente ano - sintetizando todos estes achados, ao final, na proposição de tarefas àquelas e àqueles que, em seu fazer cotidiano, produzem não apenas a saúde em termos gerais, mas também todo um modo de fazer e pensar sobre a saúde mental.

\section{MÉTODO:}

Ou como e por que falar sobre saúde mental em contextos de pandemia e isolamento social?

Este artigo constrói-se a sob o formato de um ensaio teórico-crítico (MENEGHETTI, 2011). É estruturado, também, em um diálogo, inspirado no formato de revisão narrativa da literatura (ROTHER, 2007), com os três únicos estudos publicados junto à revista The Lancet ${ }^{1}$, entre os meses de janeiro e junho de 2020, quando pesquisamos, em associação, os descritores "Saúde Mental" (Mental Health) e "COVID-19".

A inspiração na revisão de literatura, baseada nos estudos supracitados, que serão apresentados mais à frente, dá-se por considerarmos importante ter recursos teórico-conceituais suficientes para pensarmos sobre o que é e como produzir saúde mental em um contexto histórico atravessado pela vivência de uma pandemia. Logo, em diálogo com Rother (2007), o que queremos é produzir lastro para as reflexões que ensejamos, por conseguinte, realizar - pensando práticas profissionais em saúde em contextos de pandemia e isolamento social, mas conectadas com o que já se tem produzido e com quem já pensou sobre tais questões antes de nós. Assim, diz-nos a autora:

Os artigos de revisão, assim como outras categorias de artigos científicos, são uma forma de pesquisa que utilizam de fontes de informações bibliográficas ou eletrônicas para obtenção de resultados de pesquisas de outros autores, com o objetivo de fundamentar teoricamente um determinado objetivo (ibidem, p. v, grifo nosso).

\footnotetext{
${ }^{1}$ A Revista The Lancet foi escolhida por ser, hoje, mundialmente considerada a maior revista na área de medicina e saúde em geral. Criada em 1823, é atual e semanalmente publicada pela Elsevier, via Lancet Publishing Group, no Reino Unido, sendo
}

Isto dito, frise-se que o que objetivamos fazer aqui, logo, é mais do que uma revisão da literatura atual. $\mathrm{O}$ que queremos, em verdade, e também metodologicamente, é pensar a conjuntura atual vivida no Brasil, a partir das medidas assumidas pelo Governo Federal, frente à pandemia em tela - ponto em que, criticamente, nos propomos também a analisar um conjunto selecionado de notícias de diferentes jornais sobre os comportamentos deste mesmo governo durante a pandemia. Queremos, assim, conjeturar o que se revela frente ao povo brasileiro e às nossas trabalhadoras e trabalhadores da saúde como demandas de nosso tempoespaço, se nosso objetivo maior, enquanto profissionais, for o de produzir uma saúde implicada com a vida e o cotidiano das pessoas. Por isto é que nos propomos à construção de um ensaio teórico-crítico.

Nas palavras de Meneghetti (2011), um ensaio configura-se como um construto teórico em que se apresentam ideias concatenadas, que podem estar conectadas com estudos anteriores no campo/área em discussão, mas no sentido da crítica ou da defesa destas mesmas ideias, a partir do leque teórico e epistemológico que baseia o pensamento de suas autoras e autores. Por assim o ser, o ensaio não objetiva concluir ou arrematar nada em caráter determinante ou determinista, mas sim arguir a ciência posta e problematizar os conhecimentos que temos sobre determinada coisa, de forma a que, a partir de uma imersão e emersão crítica, nos seja possível tecer considerações contemporâneas sobre esta mesma coisa; inclusive, abrindo margem a responder a problemas modernos de formas modernas, ou a problemas antigos de formas não antigas. Destarte, para pensar a postura da/o ensaísta, vale citar Meneghetti (2011):

O ensaísta precisa transgredir a forma convencional e tradicional de pensar a realidade, pois só assim pode gerar conhecimento original e diferenciado. O ensaísta é antes de tudo experimentador e não reprodutor de conhecimento ou produto de reflexões presas à formalidade do método (ibidem, p. 330-331, grifo nosso).

À vista disso, feitas as considerações sobre os três únicos estudos encontrados e selecionados, que serão devidamente apresentados no tópico subsequente, e com os quais ensejaremos dialogar, em um momento seguinte ensejamos também apresentar uma análise crítica da realidade brasileira, a partir do conjunto selecionado de notícias que evidenciam as posturas e a política de nosso

todos os seus artigos de livre acesso, inclusive por via das mídias digitais. A saber, a revista pública estudos de âmbito nacional e internacional, inclusive a partir de pesquisas latino-americanas e brasileiras. 
atual Governo Federal. Destas análises é que queremos, ao final, apontar quais possíveis tarefas nós vislumbramos às trabalhadoras e trabalhadores da saúde, por compreendermos que será a partir delas/es que poderemos estruturar reflexões e ações efetivas de enfrentamento à pandemia que ora vivenciamos, em sua dimensão real (posto o coronavírus) e em sua dimensão simbólica (posta a desigualdade social brasileira).

\section{RESULTADOS E DISCUSSÃO:}

Ou o que nos diz a saúde mental sobre contextos de pandemia e isolamento social?

\section{Análises Teóricas a partir da Literatura da The Lancet}

Os últimos textos publicados (e aqui selecionados a partir dos critérios já explicitados) sobre a interface entre a saúde mental e os contextos de pandemia e isolamento social partem, em geral, de um reconhecimento quase que óbvio (mas nem tanto assim): momentos como estes tendem a ser interpretados negativamente pela população, incidindo, sobre esta, em efeitos autorreferidos como "ruins". Brooks e colaboradores (2020), em estudo realizado a partir do King's College London, no Reino Unido, intitulado "O Impacto Psicológico da Quarentena e como reduzi-lo: Revisão Rápida das Evidências" (tradução nossa), dizem-nos que:

Normalmente, a quarentena é uma experiência ruim para muitos. A separação das pessoas que amamos, a perda da liberdade, incerteza quanto ao estado da doença e o tédio podem criar efeitos dramáticos. [...] Os benefícios em potencial da quarentena massiva obrigatória precisam ser medidos com cuidado juntamente aos custos psicológicos. O uso com sucesso da quarentena como uma medida de saúde pública requer que tenhamos uma redução dos efeitos negativos associados (BROOKS et al, 2020, p. 912, tradução nossa, grifo nosso).

Daqui, vemos uma importante demarcação, sem a qual não podemos prosseguir: o reconhecimento dos impactos psicossociais de uma pandemia e das decorrentes medidas de isolamento social não devem ser desconsiderados pelas autoridades sanitárias, na medida em que tais efeitos, em curto e médio prazo, podem gerar impactos à própria oferta de bens e serviços de saúde à população.

Isto encontra coro no estudo de Moreno e colaboradores (2020), intitulado "Como os Cuidados em Saúde Mental devem mudar como Consequência da Pandemia de COVID-19" (tradução nossa), envidado a partir de uma articulação internacional de pesquisadoras e pesquisadores das Américas e da Europa, incluindo usuários de serviços e líderes prestadores de cuidados, quando estes nos dizem que a COVID-19 resultou em um aumento dos fatores de risco conhecidos por nós para questões configuradas como possíveis problemas de saúde mental. Dizem-nos que, juntamente com a imprevisibilidade e a incerteza, contextos de epidemias/pandemias e isolamento social podem nos levar, coletivamente, a fenômenos como "perda de renda; solidão; inatividade; acesso limitado a serviços básicos; aumento da má alimentação, consumo de álcool e jogos de aposta on-line; e diminuição do apoio familiar e social" (este último com destaque para as pessoas idosas e/ou mais vulneráveis) (MORENO et al, 2020, p. 01, tradução nossa).

Todos estes fatores, sinalizados anteriormente, devem acender um sinal de alerta das autoridades sanitárias, em termos de como cuidar das questões infectocontagiosas que uma pandemia invariavelmente ocasiona, mas sem deixar de lado todas as ressonâncias, também ao nível da saúde, que acabam por acometer a população, e que não dizem respeito somente ao microrganismo o qual estejamos combatendo. Vide:

As disparidades raciais e étnicas na incidência de COVID-19 (e mortalidade associada) foram pronunciadas. A desaceleração da economia causada pela COVID-19 levará ao desemprego, insegurança financeira e pobreza, que dificultam o acesso aos serviços de saúde (especialmente em sistemas baseados em seguros), causando efeitos deletérios na saúde física e mental e na qualidade de vida (MORENO et al, 2020, p. 01, tradução nossa, grifo nosso).

Tais condições, contudo, não são inteiramente novas. Em termos da saúde mental, os três estudos com os quais estamos aqui dialogando consensuam com a ideia de que os impactos psicossociais são inegáveis frente ao contexto de pandemia e isolamento social que estamos vivenciando; muito embora este contexto não traga, apenas, elementos novos, como muitas pessoas e pesquisas mais frágeis querem acreditar, mas sim atualize condições de acessos e inacessos à saúde e condições adoecedoras socialmente influenciadas anteriores à vivência da pandemia e do isolamento social (BROOKS et al, 2020; MORENO et al, 2020; PIERCE et al, 2020).

Matthias Pierce e colaboradores (2020), em estudo longitudinal realizado com mais de quarenta mil famílias britânicas, antes e durante a pandemia do novo coronavírus, de nome "Saúde Mental antes e durante a Pandemia de COVID-19: Uma Pesquisa de Amostra de Probabilidade Longitudinal da População do Reino Unido" (tradução nossa), nos revelam alguns dados importantes acerca deste debate, inclusive pensados a 
partir de critérios de gênero e idade, frente, também, à realidade do Reino Unido. Dizem-nos em seus estudos que já se identificavam grupos na população que apresentavam uma maior prevalência de sofrimento psíquico antes mesmo da pandemia - a partir de critérios como raça, etnia, gênero, classe, idade, acesso à renda, acesso à escolarização, entre outros. No entanto, reiteram que, à medida que as consequências econômicas do isolamento social se desenvolveram, destacando-se a recessão econômica em vigor, acredita-se ser razoável esperar um aumento não apenas dos números envolvendo casos de sofrimento psíquico em caráter mais prolongado, mas também de algo a que chamam de uma gradativa "deterioração clinicamente significativa da saúde mental" para pessoas específicas, em grupos específicos - com risco, inclusive, de aumento das taxas de suicídio e das internações psiquiátricas/hospitalares involuntárias, por situações de adoecimento mental. E quais grupos se destacam? "Mulheres, jovens e pessoas com crianças em idade pré-escolar", dizem-nos, são os que "estão experimentando o maior aumento em termos do sofrimento mental" (PIERCE et al, 2020, p. 08-09, tradução nossa).

Agora, cabe-nos arguir os estudos já citados: quais os elementos considerados (e autorreferidos) como possiveis "fatores estressores", que poderiam, assim, associar-se a esse agravamento de quadros à saúde mental, nos termos já apresentados?

É a partir de Brooks e colaboradores (2020) e de Pierce e colaboradores (2020) que podemos começar a responder a tal pergunta. Revelam-nos estes estudos que, entre os fatores estressores mais autorreferidos durante a vivência de contextos de pandemia anteriores, temos: tempo de duração da quarentena; medo da infecção; frustração e tédio; suprimentos inadequados (com destaque para as trabalhadoras e trabalhadores da saúde); e informações inadequadas. Já entre os fatores estressores autorreferidos após a vivência da pandemia, registram-se, em síntese, dois grandes pontos: o medo com relação às finanças/economia (para todas as pessoas) e o medo de sofrer com o estigma (para as pessoas contaminadas e curadas).

Sobre o medo do estigma, o qual vale à pena destacar, novamente são Brooks e colaboradores (2020) quem nos sinalizam que "educação sobre a doença [ou em educação em saúde] e os motivos da quarentena, junto com informações de saúde pública dadas à população, podem ser benéficos na redução do estigma" (ibidem, p. 917, tradução nossa, grifo nosso).

Já sobre a dimensão das condições de vida e da economia, dizem-nos também, mais especificamente, que "perdas financeiras podem ser um problema durante a quarentena, com pessoas sem poder trabalhar e tendo que interromper suas atividades sem planejamento prévio, com efeitos que aparentam ser de longo prazo" (ibidem, p. 916, tradução nossa). Mas complementam tal afirmação com o reconhecimento da necessidade de oferta de maiores cuidados estatais, ao considerar que estas pessoas, que passam pela vivência de uma quarentena, e que têm menor renda familiar, podem, muito provavelmente, necessitar de níveis maiores de suporte - suporte este, por obrigação, necessário de maior estruturação a partir dos sistemas públicos de saúde, conforme defendem Moreno e colaboradores (2020).

Os mesmos autores ainda afirmam, todavia, que esses fatores, dentre outros, podem incidir sobre a saúde mental mesmo em pessoas previamente consideradas como saudáveis, também afetando negativamente aquelas com transtornos mentais pré-existentes. $\mathrm{O}$ colapso econômico, destaca-se novamente, que provavelmente ocorrerá após a pandemia - como visualizado em exemplos epidêmicos/pandêmicos anteriores - pode exacerbar as disparidades já existentes nos níveis de assistência à saúde, e provavelmente tenderá a afetar mais desproporcionalmente as pessoas e grupos em maior risco, decorrente da desigualdade social, destacando-se aqui os pertencentes a grupos étnico-raciais não-brancos, que, dizem-nos, "têm pior acesso à assistência médica e recebem atendimento de qualidade inferior às populações brancas" (ibidem, p. 01, tradução nossa). E arrematam:

Cedo ou tarde, os sistemas de saúde serão confrontados com uma demanda generalizada para atender a essas necessidades de saúde mental relacionadas à COVID-19. Organizações internacionais, incluindo a OMS, defendem a integração da saúde mental e do apoio psicossocial na resposta à COVID-19, e um resumo de políticas da ONU sugere que os investimentos agora reduzirão os efeitos na saúde mental posteriormente (ibidem, p. 01, tradução nossa, grifo nosso).

Se quisermos, a partir daqui, envidar esforços para refletir sobre o trabalho na saúde, frente à COVID-19, necessário destaque seja feito ao que os estudos, portanto, nos apontam sobre trabalhadoras/es da saúde frente a contextos de pandemia e isolamento social, especialmente aquelas e aqueles que se encontram na linha de frente do enfrentamento a tais contextos. Isto porque, entre estas próprias trabalhadoras e trabalhadores, os estudos aqui selecionados revelam os riscos que contextos de pandemia e isolamento social podem causar a este público. Entre os sintomas relatados, como exemplos, veremos: "[...] exaustão, desprendimento de outros, ansiedade em lidar com pacientes febris, irritabilidade, insônia, baixa concentração e capacidade de tomada de decisões, performance no trabalho progressivamente pior e relutância em trabalhar ou até mesmo a consideração da 
possibilidade de pedir desligamento" (BROOKS et al, 2020, p. 913, tradução nossa); sintomas estes comumente associados ao TEPT (Transtorno de Estresse PósTraumático).

Como métodos possíveis para mitigar tais impactos psicossociais decorrentes da vivência de uma pandemia, são novamente Brooks e colaboradores (2020) quem nos indicarão sugestões, e com a devida atenção às/aos profissionais na saúde. Em síntese, sugerem-nos que: $\left(1^{\circ}\right)$ o Estado procure meios para que as medidas de isolamento social, com responsabilidade, sejam as mais curtas possíveis; $\left(2^{\circ}\right)$ seja fornecido o máximo de informação qualificada possível às trabalhadoras/es e à população como um todo; $\left(3^{\circ}\right)$ sejam garantidos, também pelos governantes, meios de subsistência e os suprimentos adequados; $\left(4^{\circ}\right)$ sejam pensadas estratégias de redução do tédio e melhoria das comunicações; $\left(5^{\circ}\right)$ seja dada às/aos trabalhadoras/es da área de saúde uma atenção especial; e $\left(6^{\circ}\right)$ que sejam pensadas estratégias de estímulo a um certo sentimento de solidariedade, em que as pessoas se sintam convidadas a enfrentarem o contexto pandêmico de forma coletiva.

Logo, ao nível da implicação social e coletiva, na linha da defesa da solidariedade, concluem levantando possíveis "tarefas" que dialoguem com as sugestões acima, muitas das quais serão melhor desenvolvidas a partir do conjunto de profissionais da saúde:

Se a quarentena é essencial, então nossos resultados sugerem que as autoridades devem adotar cada medida para assegurar que esta experiência seja a mais tolerável possível. Isso pode ser alcançado de várias formas: contando para as pessoas o que está acontecendo e os motivos para isso, explicando por quanto tempo isso vai continuar, fornecendo atividades significativas para que possam fazer, fornecendo uma comunicação transparente, assegurando suprimentos básicos (como água, comida e remédios) e reforçando o senso de solidariedade (BROOKS et al, 2020, p. 919, tradução nossa, grifo nosso).

Dialogando com esta mesma perspectiva, Moreno e colaboradores (2020) nos sinalizam que a pandemia decorrente do novo coronavírus deveria, então, nos ser suficiente para defender a ideia de que os sistemas públicos deveriam incluir a saúde mental como questão prioritária, tendo em vista os agravos visualizados em diferentes níveis da vida em sociedade. Além disso, nos apontam que tais ações poderiam qualificar a oferta de serviços em saúde mental, na medida em que reduzem a disparidade de acessos a bens e serviços de saúde.

As implicações econômicas da pandemia de COVID-19 são sérias. [...] Cuidados de saúde mental de baixa qualidade, baseados em acessibilidade sem avaliação da qualidade ou monitoramento das necessidades e da sua eficiência, contribuirão apenas para aumentar as desigualdades e o agravamento da saúde mental em todo o mundo. Agora, mais do que nunca, precisamos implementar a prestação de serviços que atendam às necessidades de saúde $\mathrm{e}$ reduzam disparidades, tanto globalmente quanto em países individualmente. [...] [Tais ações] poderiam transformar a pandemia de COVID-19 em uma oportunidade de melhorar os cuidados de saúde mental para todos (MORENO et al, 2020, p. 08, tradução nossa, grifo nosso).

Não obstante, é basilar considerar o que nos apontam Pierce e colaboradores (2020), na conclusão de seu estudo. Dizem-nos eles que a pandemia resultante da COVID-19 produziu muitos novos desafios para a pesquisa em saúde, para as Políticas Públicas e para a oferta de serviços de saúde. Contudo, os impactos psicossociais do que vivemos frente à COVID-19 e as respostas governamentais a esta pandemia, em nível global, não se revelam como necessariamente novos. Partindo-se de tal reconhecimento, este poderia ser um momento oportuno em que as desigualdades sociais, que produzem efeitos à saúde mental, pudessem ser mais frontalmente combatidas; o que, certamente, amplia ainda mais o nosso desafio, enquanto trabalhadoras $\mathrm{e}$ trabalhadores da saúde - quanto mais se considerarmos, para efeitos desta análise, a história e a contemporaneidade do Brasil.

\section{Análises Críticas a partir da Experiência Brasileira}

O ano de 2020 se iniciou, no Brasil, sob profundas marcas das contrarreformas neoliberais adotadas pelo Governo Federal, a partir da precarização das relações trabalhistas e do desfinanciamento das políticas sociais estratégicas para o enfrentamento à pobreza, além da própria crise política, sustentada pela contínua ameaça à democracia e amparada na manipulação ideológica conservadora e carregada pelas Fake News.

É neste cenário emblemático e de insegurança social que o país recebe a COVID-19, oficialmente, em março deste mesmo ano. Isto nos leva a uma inquietação imediata: como assumir, no Brasil, as medidas sugeridas pelos estudos anteriores, frente a um Estado em colapso? As respostas brasileiras não foram compatíveis com tais recomendações, e nos levaram ao topo crítico da pandemia em escala global, o que, no âmbito das notícias, fartamente se vê. Notemos: as medidas do Governo Federal brasileiro se mostraram insuficientes, levando o mesmo a ser denunciado em um conjunto de organismos internacionais, acusando-o de "crimes contra a humanidade" e "genocídio", havendo ainda ações 
específicas em relação aos povos indígenas e às pessoas em situação de prisão, altamente afetadas por conta da contaminação pelo novo coronavírus (BRAUN, 2020; CHADE, 2020; BERGAMO, 2020; PARANHOS, 2020). As primeiras declarações do Governo Federal negligenciaram os riscos postos pela doença, sendo a mesma relativizada como uma "gripezinha" (SILVA; PASTI, 2020). Os conflitos na gestão, levaram, inclusive, à substituição de dois Ministros da Saúde, em um intervalo de menos de um mês, onde ambos estiveram pressionados pela adoção de medidas federais em desacordo às expectativas sanitárias e científicas oficiais (ZYLBERKAN; CAMPOS, 2020), como: boletim médico diário em horários irregulares; boletins epidemiológicos sobre o avanço da doença desatualizados; banco de dados cadastrais de profissionais da saúde desatualizado; aquisição e uso de tecnologias e terapêuticas não reconhecidas oficialmente para o tratamento da COVID19, entre outros problemas (COSTA, 2020; JANSEN, 2020; MALI, 2020; CASTANHO, 2020).

Logo, o que vemos é que as ações do Governo Federal não estiveram coordenadas, intersetoriais e/ou mesmo matricializadas, levando a fragilidades substanciais do ponto de vista da mitigação dos riscos de tal desastre e da assistência integral a toda a população, acentuando desigualdades históricas que afetam diferentemente o povo brasileiro - ocasionando, inclusive, no crescimento de ações não sincronizadas entre União, estados e municípios. E, em termos da vida cotidiana, exemplos não nos faltam de como fomos afetados em muitas e distintas esferas: $\left(1^{\circ}\right)$ no trabalho, vemos o aumento do desemprego e da instabilidade, fruto da flexibilização dos direitos trabalhistas, por meio de medidas provisórias que beneficiaram grandemente os empregadores (SILVEIRA, 2020); $\left(2^{\circ}\right)$ o auxílio emergencial foi solicitado por mais de 124 milhões de pessoas, escancarando a situação de extremo pauperismo nacional (MENDONÇA, 2020); (3º) a assistência social está à frente da organização de ações de garantia de acesso à alimentação, retomando as velhas práticas de entrega de cestas básicas, considerando o aumento da situação de fome crescente no país (MARCONDES, 2020); (4º nos grandes centros urbanos, todos os esforços foram concentrados na atenção à população em situação de rua, buscando ofertar condições mínimas de sobrevivência a esta população, tida como a em maior risco (LIMA; CHARLEAUX, 2020); e (5) na educação, com a exigência do isolamento social, a adoção do ensino remoto escancarou as desigualdades sociais, criando abismos entre o ensino público e o privado (OLIVEIRA, 2020).

Todo este cenário é, em si, reconhecido por nós como um potencial produtor de adoecimento(s) psíquico(s) - basta dialogarmos com os achados dos estudos apresentados anteriormente (BROOKS et al,
2020; MORENO et al, 2020; PIERCE et al, 2020) sustentado por uma política nacional neoliberal, meritocrática e estruturada no medo, onde o salve-se quem puder coloca-se como expressão de ordem. Na divisão entre os que podem se manter em isolamento social e os que estão nas ruas, seja pelas condições socioeconômicas díspares, sejam as trabalhadores e trabalhadores que garantem a continuidade dos serviços essenciais, muito embora tratem-se de situações extremamente distintas, o que reconhecemos é que produzem-se formas de sofrimento e de adoecimento, especialmente por estarem, todas estas pessoas, em seus diferentes lugares, vitimadas pela negligência e por uma política nacional genocida, que esfacela o tecido social, as relações e as redes de proteção individual e comunitária, matando tanto quanto, ou mais, do que o próprio coronavírus.

No entanto, há, em nossa mirada, um abismo social ainda maior, colocado como horizonte diante da pandemia no Brasil, sustentado pelo que tem sido chamado de negacionismo, com a minimização e/ou relativização do momento que vivemos, sem que se observe, com a devida importância, este nosso contexto, este nosso momento histórico. Isto revela-nos, ainda que (não tão) implicitamente, a adoção de uma contumaz política de morte por parte do atual Estado brasileiro ainda que, reconheçamos, as ações em nível estadual e municipal tenham sido, em muitos casos, contrastantes com aquelas indicadas em nível federal, e até mesmo mais implicadas com a gravidade da pandemia que estamos a vivenciar. Conquanto, tal situação tem direcionado a responsabilidade pelo atual cenário social quase que exclusivamente a um grupo específico, formado pelas/os profissionais de saúde, convocadas/os à "salvação" do povo brasileiro, mas sem valorização de sua atuação e/ou condições de trabalho suficientes para tal empreitada. Vale, ainda, menção ao fato de que as trabalhadoras e trabalhadores da saúde se encontram em pleno processo de precarização de suas condições de trabalho desde antes da pandemia em tela, postos todos os projetos neoliberais de sucateamento e precarização das próprias políticas de saúde, ao longo da história do Brasil - fatos estes que, agora, acabam por ser mais notórios e escancarados, cobrando de nós o seu preço simbólico.

É pelo reconhecimento destes impactos psicossociais oriundos do contexto de pandemia e isolamento social que temos vivenciado, atrelado a esta constatação de que a responsabilidade acaba por recair nas mãos das trabalhadoras e trabalhadores da saúde, deveras abandonadas/os em seu saber-fazer profissional por parte do aparato estatal nacional que deveria ampará-las e ampará-los, que nos propomos, a partir de agora, a sintetizar possíveis tarefas que se revelam a estas/es profissionais, se queremos assumir um compromisso, frente ao povo brasileiro, de produzir formas reais, 
efetivas e implicadas de enfrentamento a esta pandemia e aos seus decorrentes impactos.

\section{CONSIDERAÇÕES FINAIS:}

$\mathrm{Ou}$, em síntese, quais tarefas se revelam às trabalhadoras e trabalhadores da saúde, hoje?

Defronte às reflexões apresentadas até aqui, a primeira tarefa que vislumbramos é a garantia da execução dos serviços essenciais. Partimos do reconhecimento de que estas/es profissionais não se encontram frente ao cenário perfeito para a execução de suas práticas, mas também partimos da compreensão de que, sem estas/es, a ausência da oferta de serviços de saúde no país, neste momento, representaria um agravamento dos fossos ocasionados pelas desigualdades estruturais de acesso à saúde que vivemos historicamente. Logo, a primeira tarefa implicaria em assegurar que todas as pessoas mantenham a sua possibilidade de acessar bens e serviços de saúde, inclusive no campo da saúde mental, bem como demais especialidades.

A segunda tarefa que vislumbramos se dá a partir de um compromisso absolutamente inegociável com a informação e a comunicação em saúde, com a veiculação de informações qualificadas. Disseminar informações qualificadas no sentido, inclusive, de combater Fake News, evidenciando aquilo que é inadequado, que é mentiroso, que não dialoga com as reais necessidades da população - inclusive se essas notícias falsas forem divulgadas pelas próprias autoridades. As trabalhadoras e trabalhadores da saúde, se organizadas/os, têm condição de evidenciar aquilo que não é procedente, produzindo uma postura de enfrentamento a notícias falsas, estimulando o conhecimento franco do que estamos vivendo ante a toda a população.

A terceira tarefa que vislumbramos, e que dialoga com a anterior, é a de que, partindo-se desta divulgação de informações qualificadas, possamos produzir no país, em caráter concomitante, uma postura de evitação ao pânico, mas atrelada a um convite à responsabilização coletiva, no sentido de evidenciar que o pânico não nos ajuda a construir bons caminhos, mas a desresponsabilização, a negação, ou "não enxergar" a realidade do que estamos vivendo, também não constrói.

A quarta tarefa que vislumbramos e, para nós, talvez, uma das mais importantes, é a de evidenciar todos os grupos em maior risco, por conta de nossas desigualdades estruturais. Discutir saúde mental, nesse sentido, é dizer que as condições de saúde de pessoas que se encontram em condições desiguais por classe, raça, gênero, deficiência, idade, entre outros, são efetivamente piores. Essas pessoas estão mais suscetíveis ao agravamento de seu sofrimento do que pessoas outras, que estejam em melhores condições sociais, políticas e econômicas.

A quinta e penúltima tarefa, essa também inegociável, é a de defender as nossas Políticas Públicas, com destaque para os Sistema Único de Saúde (SUS) e Sistema Único de Assistência Social (SUAS). Toda a trabalhadora e todo o trabalhador que, de fato, queira que tenhamos maiores e melhores condições de enfrentar esta pandemia, deve, coletivamente e neste momento, assumir uma implicação inegociável com estes nossos sistemas, públicos, gratuitos e de qualidade.

Por fim, a sexta e última tarefa é reconhecer que todas as tarefas anteriormente citadas não são e nem podem ser exclusivas do setor saúde ou individualmente atribuídas às trabalhadoras e trabalhadores da saúde, como se fossem obrigações inalienáveis a estes. No entanto, tal processo não pode dar-se sem o reconhecimento destas/es enquanto classe trabalhadora. Entender sistemicamente a correlação de forças que produz esta situação de pandemia, analisando criticamente o cenário brasileiro, é um dever ético-político, que implica, em suma, não apenas a estas trabalhadoras/es, mas a todas e todos nós, coletivamente, exigindo transformações estruturais frente à sociedade brasileira. Talvez, inclusive, esta seja a nossa tarefa mais importante, porque, e a história nos comprova, apenas os movimentos efetivamente coletivos e éticopoliticamente implicados com a produção do comum e a defesa da vida configuram novos horizontes societários possíveis, equânimes e justos.

\section{REFERÊNCIAS}

ALVES, A. A. M.; RODRIGUES, N. F. R. Determinantes Sociais e Econômicos da Saúde Mental. Rev. Port. Sau. Pub., Lisboa, v. 28, n. 02, p. 127-131, 2010.

AMARANTE, Paulo. Saúde Mental e Atenção Psicossocial. Rio de Janeiro: Editora Fiocruz, 2007. 120 p.
BERGAMO, M. Bolsonaro é denunciado à ONU por descaso na proteção dos povos indígenas. Folha de São Paulo, 2020. Disponível em: <https://cutt.ly/hdlnXgM>. Acesso em: 30 Jul. 2020.

BRAUN, J. Bolsonaro é denunciado na ONU por ataques contra jornalistas. Veja, 2020. Disponível em: <https://bityli.com/sfq6s>. Acesso em: 30 Jul. 2020. 
BROOKS, S. K. et al. The psychological impact of quarantine and how to reduce it: rapid review of the evidence. Lancet, v. 395, p. 912-920, 2020. D.O.I.: <https://doi.org/10.1016/S0140-6736(20)30460-8>.

CASTANHO, W. Alexandre de Moraes manda governo Bolsonaro retomar divulgação de dados totais da Covid-19. Folha de São Paulo, 2020. Disponível em: <https://cutt.ly/JdlQHrX>. Acesso em: 30 Jul. 2020.

CHADE, J. Denúncia na ONU: Pandemia aprofunda política genocida do governo em prisões. UOL Notícias, 2020. Disponível em: <https://bityli.com/yCF2L>. Acesso em: 30 Jul. 2020.

COSTA, C. Pesquisadores divulgam documento contra a liberação do uso de cloroquina sem comprovação científica. O Globo, 2020. Disponível em: <https://cutt.ly/Fdlm0D8>. Acesso em: 30 Jul. 2020.

FUNDAÇÃO OSWALDO CRUZ (FIOCRUZ). Saúde Mental e Atenção Psicossocial na Pandemia COVID19. Boletim Online da Fundação Oswaldo Cruz (FIOCRUZ), 2020.

INTER-AGENCY STANDING COMMITTEE (IASC). Como lidar com os aspectos psicossociais e de saúde mental referentes ao surto de COVID-19. Boletim Online da Inter-Agency Standing Committee (IASC), v. $1.5,2020$.

JANSEN, R. Metade dos médicos relata pressão para dar remédio sem comprovação científica. $O$ Estado de S. Paulo (Estadão), 2020. Disponível em: <https://cutt.ly/odlQpDD>. Acesso em: 30 Jul. 2020.

LIMA, J. D.; CHARLEAUX, J. P. Quais as medidas para a população de rua na pandemia. Nexo Jornal, 2020. Disponível em: 〈https://cutt.ly/sdlW3kV〉. Acesso em: 30 Jul. 2020.

MALI, T. Ministério da Saúde usa dados incompletos e desatualizados em boletins sobre COVID-19. Poder360, 2020. Disponível em: <https://cutt.ly/QdlQn7E>. Acesso em: 30 Jul. 2020.

MARCONDES, D. A fome durante a pandemia: "A última vez que vimos algo assim o Brasil tinha 32 milhões de miseráveis". Carta Capital, 2020. Disponível em: <https://cutt.ly/gdlWAKX〉. Acesso em: 30 Jul. 2020.

MENDONÇA, H. Metade da população brasileira foi beneficiada pelo auxílio emergencial do Governo em junho. El País (Brasil), 2020. Disponível em: <https://cutt.ly/2dlWcpk>. Acesso em: 30 Jul. 2020.

MENEGHETTI, F. K. O que é um ensaio-teórico? Rev. Adm. Contemp., Curitiba, v. 15, n. 02, p. 320-332, 2011.

MORENO, C. et al. How mental health care should change as a consequence of the COVID-19 pandemic. Lancet Psychiatry 2020, Published Online, 2020. D.O.I.: <https://doi.org/10.1016/S2215-0366(20)30307-2>.

OLIVEIRA, C. Com aulas remotas, pandemia escancara desigualdade no acesso à educação de qualidade. Brasil de Fato, 2020. Disponível em: <https://cutt.ly/qdlEaiF>. Acesso em: 30 Jul. 2020.

ORGANIZAÇÃO MUNDIAL DA SAÚDE (OMS). Considerações Psicossociais e de Saúde Mental durante o Surto de COVID-19. Boletim Online da Organização Mundial da Saúde (OMS), Organização PanAmericana da Saúde (OPAS), 2020.

PARANHOS, T. COVID-19: Bolsonaro é denunciado por genocídio no Tribunal de Haia. Metrópoles, 2020. Disponível em: <https://cutt.ly/xdlmqGf>. Acesso em: 30 Jul. 2020.

PIERCE, M. et al. Mental health before and during the COVID-19 pandemic: a longitudinal probability sample survey of the UK population. Lancet Psychiatry 2020, Published Online, 2020.2 D.O.I.: <https://doi.org/10.1016/S2215-0366(20)30308-4>.

ROCHA, R. V. S; COELHO, M. T. A. D. Pobreza e Produção de Subjetividade no Cotidiano de Usuários de um Centro de Atenção Psicossocial em Salvador/BA. In: OLIVEIRA, Walter; PITTA, Ana; AMARANTE, Paulo. (Orgs.). Direitos Humanos e Saúde Mental. $1^{a}$ ed. São Paulo: Hucitec Editora, p. 406-449, 2017.

ROTHER, E. T. Revisão Sistemática X Revisão Narrativa. Acta Paul. Enferm., São Paulo, v. 20, n. 02, p. v-vi, 2007.

SILVA, R.; PASTI, D. Da "gripezinha" ao "e daí?": as falas de Bolsonaro em cada fase da pandemia. A Gazeta, 2020. Disponível em: 〈https://cutt.ly/vdlmlwZ〉. Acesso em: 30 Jul. 2020.

SILVEIRA, D. Desemprego diante da pandemia tem alta pela $4^{\text {a }}$ semana seguida, aponta IBGE. G1, 2020. Disponível em: <https://cutt.ly/adlQ8AN>. Acesso em: 30 Jul. 2020. 
ZYLBERKAN, M.; CAMPOS, J. P. Queda de dois Veja, 2020. Disponível em: <https://cutt.ly/0dlmE3M>. ministros em apenas um mês deixa Saúde à deriva. Acesso em: $30 \mathrm{Jul}$. 2020. 